\title{
Survey of Oxidase-Positive and -Negative Bacteria Using a Quantitative Kovacs Oxidase Test
}

\author{
PETER JURTSHUK, JR., AND DONALD N. MCQUITTY \\ Department of Biology, University of Houston, Houston, Texas 77004
}

\begin{abstract}
A manometric assay system employing ascorbate and $N, N, N^{\prime}, N^{\prime}$-tetramethyl-p-phenylenediamine (TMPD) was used to quantitate terminal oxidase activity in bacterial non-proliferating whole cells. A wide variety of physiologically diverse bacteria, all of which were grown heterotrophically, was tested by this assay. For this survey study, 79 bacterial strains, which represented 34 genera, were used. Turbidimetrically standardized resting (non-proliferating) cell suspensions were prepared from cells harvested at the late logarithmic growth phase; all cells were grown under identical nutritional conditions. The TMPD oxidase activity obtained quantitatively correlated exceptionally well with results of the standard Kovacs oxidase test. In fact, the increased sensitivity of this quantitative assay allowed for further reclassification within the two major divisions of Kovacs oxidase-positive and -negative groups. Groups I and II contained all of the oxidase-positive microorganisms and the bacteria listed in group I had the highest TMPD oxidase rates, the $\mathrm{Q}_{\mathrm{O}_{2}}$ values (microliters of $\mathrm{O}_{2}$ consumed per hour per milligram [dry weight] at $30 \mathrm{C}$ ) ranging from 393 to 2,164 . The organisms listed in group II still had moderately high TMPD oxidase activity, the $\mathrm{Q}_{\mathrm{O}_{2}}$ values ranging from 27 to 280 . All oxidase-negative bacteria fell into groups III and IV. Bacteria in group III had low but still measurable TMPD oxidase rates, the $\mathrm{Q}_{\mathrm{O}_{2}}$ values ranging from 3 to 33 , whereas the bacteria found in group IV were inert and unable to oxidize TMPD. A grouping analysis allowed for the resolution of that point which separates oxidase-positive from oxidase-negative bacteria. This point, for non-proliferating cells, was found to be an absolute TMPD oxidation $\mathrm{Q}_{\mathrm{O}_{2}}$ value of 33 (after correcting for the endogenous rate by subtraction) and a $Q_{O_{2}}$ (TMPD/endogenous) ratio of 5; the latter parameter indicated that the uncorrected TMPD oxidation $\mathrm{Q}_{\mathrm{O}_{2}}$ value had to be five times greater than the rate for endogenous respiration. All Kovacs oxidase-positive organisms were found to have TMPD oxidase $\mathrm{Q}_{\mathrm{O}_{2}}$ values greater than these two metabolic parameters, whereas all Kovacs oxidase-negative organisms had lower values.
\end{abstract}

Conover (3), studying cytochrome oxidase activity in calf thymus nuclei, demonstrated that $N, N, N^{\prime}, N^{\prime}$ - tetramethyl-p-phenylenediamine (TMPD) oxidation readily measured cytochrome oxidase activity in intact nuclei preparations, whereas cytochrome $c$ oxidation could not be used for such determinations. Reduced TMPD readily penetrated the nuclear membrane barrier and allowed for the full expression of the terminal oxidation rate. The comparative cytochrome $c$ oxidase rate was only fully expressed when either (i) detergent was added to the intact nuclei preparation, or (ii) when the latter was treated by sonic irradiation. This observation and one made by our laboratory, which showed that one could precisely and quantitatively measure terminal oxidase activity in non-proliferating bacterial whole cells using Azotobacter vinelandii (8) and Neisseria species (10), suggested that this technique could be applied to measure terminal oxidase activity in other bacteria. Our findings (8) indicated that reduced TMPD readily penetrated the $A$. vinelandii whole cell and that TMPD could be oxidized by the membranebound cytochrome-dependent terminal oxidase associated with the electron transport particle in a manner identical to that carried out by the intact calf thymus nuclei preparations. The non-proliferating $A$. vinelandii whole cells could not oxidize cytochrome $c$ even though the electron transport system of $A$. vinelandii does have the capability of carrying out this oxidation reaction (13). Studies which employed varying TMPD concentrations also showed that the reaction kinetics exhibited by the $A$. vinelandii whole cells (8) were almost identical to those previously noted for the Azotobacter elec- 
tron transport particle $(7,9)$. Previously, both the TMPD and cytochrome $c$ oxidase activities were shown to be exclusively associated with the particulate membrane-bound enzymes found in the Azotobacter $\mathrm{R}_{3}$ electron transport fraction $(7,9,12,13)$. In an analogous type of study with different Neisseria species (a strongly oxidase-positive group of organisms), it was shown that the TMPD oxidase rate for whole cells was at least 10 to 20 times greater than that noted for growth substrate oxidations (10), and again it was possible to establish with two organisms of this genus ( $N$. catarrhalis and $N$. flava) that TMPD oxidase activity was exclusively associated with the electron transport particle (11). These results led us to conclude that this type of TMPD oxidase assay, which employs metabolically active, non-proliferating whole cells specifically turbidimetrically standardized resting-cell suspensions, would be useful in examining a large variety of heterotrophically grown organisms in order to determine the extent, or degree, to which TMPD oxidation occurred. The TMPD oxidase rate, or the $Q_{\mathrm{O}_{2}}$ value for TMPD oxidation, could be quantitatively estimated for a variety of different bacteria, and this value could then be analyzed in a comparative manner as it is currently performed (qualitatively) for the Kovacs oxidase test $(14,21)$. The unique feature of the assay described in this communication is that it is a quantitative procedure which allows for the direct estimation for the TMPD oxidase $\mathrm{Q}_{\mathrm{O}_{2}}$ value (microliters of $\mathrm{O}_{2}$ consumed per hour per milligram [dry weight] at $30 \mathrm{C}$ ) by manometry; in essence it is a "quantitative oxidative test." In theory this can be done since both the Kovacs oxidase test and the procedure described herein utilize TMPD to measure the cytochrome-dependent terminal oxidase reaction in bacteria. The use of TMPD or other $p$ phenylenediamine derivatives as electron donor dyes, for both microbiological and biochemical studies, has already been described in detail $(7-10,12)$. In principle, any $p$-phenylenediamine derivative could be used to measure terminal oxidase activity in bacterial electron transport systems of oxidase-positive organisms. The only difference would be a quantitative one, since the relative rates of this oxidation reaction would vary depending on the derivative used. A comparative study in which different $p$-phenylenediamine derivatives were used to measure terminal oxidase activity in the $A$. vinelandii electron transport particle has already been published $(9,12)$. Interestingly, the ortho- and meta- derivatives were found to be inert and could not be used to measure $A$. vinelandii terminal oxidase activity. In this communication we wish to report on a survey study in which 79 organisms, representing 36 genera of bacteria, were examined for their capability to oxidize TMPD quantitatively. A preliminary report of the data given in this communication has been presented elsewhere (12; D. N. McQuitty, O. Marcucci, and P. Jurtshuk, Abstr. Annu. Meet. Am. Soc. Microbiol. 1974, P152, p. 170).

\section{MATERIALS AND METHODS}

Microorganisms and cultural conditions. The bacterial cultures used for this survey study are listed in Table 1. The sources are identified in Acknowledgments. Non-proliferating resting-cell suspensions were prepared from cells grown at $30 \mathrm{C}$ on nutrient broth (Difco) which contained $1 \%(\mathrm{wt} / \mathrm{vol})$ sucrose supplemented with $0.5 \%$ (wt/vol) yeast extract (Difco). The marine bacteria, the Vibrio parahaemolyticus strains, and the Pseudomonas bathycetes strains were grown on this same medium to which $1.5 \%(\mathrm{wt} / \mathrm{vol}) \mathrm{NaCl}$ was added. Vitreoscilla stercoraria strains were found to be more fastidious and were grown on the same medium except that $1 \%$ (wt/vol) glucose was substituted for sucrose and the medium also contained $0.25 \%$ (wt/vol) dipotassium phosphate. All seed cultures were allowed adequate time to adapt to the above-mentioned media, and batch cultures were grown in 400-ml quantities in L-flasks that were placed on a rotary shaker (72 cycles/min). For every culture, growth was monitored turbidimetrically so that the final batch cultures were harvested (by centrifugation) at the late logarithmic phase (that point which exactly represented two-thirds of the maximal growth concentration). After centrifugation, resting-cell suspensions were prepared, suspended in $0.2 \mathrm{M}$ potassium phosphate buffer ( $\mathrm{pH} 7.5$ ), and standardized turbidimetrically so that a $1 / 100$ dilution gave a reading of 0.700 to 0.800 optical density unit at $420 \mathrm{~nm}$.

Enzyme assay conditions. The chemical and enzymological methods used in this study are identical to those previously described $(7,9)$. Manometric assays were performed at $30 \mathrm{C}$ using conventional Warburg flasks of $15-\mathrm{ml}$ capacity. All reactions were initiated by the addition of both ascorbate $(20 \mu \mathrm{mol})$ and TMPD $(10 \mu \mathrm{mol})$ from separate side arms after the initial temperature equilibration period of 7 min. The main compartment contained $33.3 \mathrm{mM}$ phosphate buffer ( $\mathrm{pH}$ 6.0), the bacterial resting-cells preparation, and deionized water to a total volume of $3.0 \mathrm{ml}$. The center well contained $0.2 \mathrm{ml}$ of $2 \mathrm{M}$ KOH solution. TMPD oxidase analyses employing resting-cell suspensions of the marine organisms were assayed both in the presence and absence of $1.5 \%(\mathrm{wt} / \mathrm{vol}) \mathrm{NaCl}$. Higher TMPD oxidase values were obtained when $\mathrm{NaCl}$ was omitted from the assay system (reported in Fig. 1). Suitable controls were always incorporated into all manometric runs so as to insure that no ascorbate oxidation had occurred in the absence of TMPD, and the necessary precautions were also undertaken to insure that no 
TABLE 1. TMPD oxidase grouping analysis of $Q_{O_{2}}$ values presented in Fig. 1

\begin{tabular}{|c|c|c|c|}
\hline Organism ${ }^{a . b}$ & $\begin{array}{l}\text { Kovacs oxi- } \\
\text { dase reac- } \\
\text { tion }\end{array}$ & $\begin{array}{l}\text { Fig. } 1 \text { abbre- } \\
\text { viation }\end{array}$ & Source ${ }^{c}$ \\
\hline \multicolumn{4}{|l|}{ Group I } \\
\hline Achromobacter xerosis (14780) & + & $\mathrm{Ax}$ & ATCC \\
\hline Aeromonas liquefaciens (14715) & + & $\mathrm{Al}$ & UTHGSBS \\
\hline Agrobacterium tumefaciens (15955) & + & Agt & ATCC \\
\hline Alcaligenes faecalis $(8750)$ & + & Alf & ATCC \\
\hline Azotobacter vinelandii $\mathrm{O}$ (12518) & + & Av & U Houston \\
\hline Azotomonas insolita (12412) & + & $\mathrm{Ai}$ & A'TCC \\
\hline Branhamella catarrhalis (25238) (N. catarrhalis) & + & $\mathrm{Nc}$ & M C Wisconsin \\
\hline Branhamella catarrhalis Gp4 (N. catarrhalis) & + & $\mathrm{Nc}$ & U Maryland \\
\hline Branhamella catarrhalis NC31 ( $N$. catarrhalis) & + & $\mathrm{Nc}$ & U Maryland \\
\hline Moraxella osloensis & + & Mo & U Maryland \\
\hline Neisseria elongata (25295) & + & $\mathrm{Ne}$ & M C Wisconsin \\
\hline Neisseria flava (14221) & + & $\mathrm{Nf}$ & M C Wisconsin \\
\hline Neisseria mucosa & + & $\mathrm{Nm}$ & Houston $\mathrm{H} \mathrm{D}$ \\
\hline Neisseria sicca & + & Ns & Houston H D \\
\hline Rhizobium meliloti F-28 & + & $\mathrm{Rm}$ & U Houston \\
\hline Rhizobium meliloti 3DOal & + & $\mathrm{Rm}$ & U Houston \\
\hline Pseudomonas acidovorans (15668) & + & Psac & ATCC \\
\hline Pseudomonas aeruginosa (15442) & + & Psa & UTHMS \\
\hline Pseudomonas bathycetes $\mathrm{C}_{2} \mathrm{M}_{2}$ & + & Psb & U Maryland \\
\hline Pseudomonas fluorescens (13525) & + & Psf & ATCC \\
\hline Pseudomonas stutzeri 320 & + & Pss & U'THGSBS \\
\hline Spirillum itersonii (12639) & + & $\mathrm{Si}$ & ATCC \\
\hline Sporosarcina ureae & + & $\mathrm{Su}$ & UTHGSBS \\
\hline \multicolumn{4}{|l|}{ Group II } \\
\hline Aeromonas hydrophila (9071) & + & $\mathrm{Ah}$ & UTHGSBS \\
\hline Flavobacterium capsulatum (14666) & + & Fc & ATCC \\
\hline Micrococcus luteus (Sarcina luteus) & + & $\mathrm{Sl}$ & U Houston \\
\hline Micrococcus luteus (S. flava) & + & Sf & UTHGSBS \\
\hline $\begin{array}{l}\text { Vibrio parahaemolyticus biotype alginolyticus } \\
156-70\end{array}$ & + & $\mathrm{Va}$ & U Maryland \\
\hline Vibrio parahaemolyticus FC1011 & + & $\mathrm{Vp}$ & U Maryland \\
\hline Vibrio parahaemolyticus SAK 3 & + & $V_{p}$ & U Maryland \\
\hline \multicolumn{4}{|l|}{ Group III } \\
\hline Acinetobacter calcoaceticus (19606) & - & Ac & ATCC \\
\hline Acinetobacter calcoaceticus 208 & - & Ac & UTHGSBS \\
\hline Arthrobacter globiformis (8010) & - & $\mathrm{Ag}$ & ATCC \\
\hline Bacillus cereus & - & $\mathrm{Bc}$ & U Houston \\
\hline Bacillus firmus (14575) & - & $\mathrm{Bf}$ & UTHGSBS \\
\hline Bacillus megaterium & - & $\mathrm{Bm}$ & U Houston \\
\hline Bacillus subtilis W-23 & - & Bs & U Houston \\
\hline Corynebacterium 7E1C (19067) & - & 7ElC & U'T Austin \\
\hline Corynebacterium diphtheriae (11913) & - & $\mathrm{Cd}$ & ATCC \\
\hline Enterobacter aerogenes & - & $\mathrm{Ea}$ & U Houston \\
\hline Escherichia coli B & - & $\mathrm{Ec}$ & U Houston \\
\hline Escherichia coli B & - & Ec & U'THGSBS \\
\hline Escherichia coli $\mathrm{B} / \mathrm{r}$ & - & Ec & UTHGSBS \\
\hline Escherichia coli $\mathrm{C}$ & - & $\mathrm{Ec}$ & UTHGSBS \\
\hline Escherichia coli Crookes & - & $\mathrm{Ec}$ & U Houston \\
\hline Escherichia coli $\mathrm{K}-12$ & - & Ec & UTHGSBS \\
\hline Escherichia coli $\mathrm{K}-12 \mathrm{~S}$ & - & Ec & U'THGSBS \\
\hline Escherichia coli $\mathrm{K}-12 \mathrm{~S}$ & - & $\mathrm{Ec}$ & U'THGSBS \\
\hline Escherichia coli $\mathrm{F}$ & - & Ec & U'THGSBS \\
\hline Escherichia coli $0111 \mathrm{a}_{1}$ & - & Ec & UTHGSBS \\
\hline Klebsiella pneumoniae M5al & - & $\mathrm{Kp}$ & U Sussex \\
\hline Mycobacterium fortuitum & - & Mf & UTHMS \\
\hline Mycobacterium phlei & - & $\mathrm{Mp}$ & U Houston \\
\hline Mycobacterium smegmatis & - & Ms & U Houston \\
\hline Micrococcus luteus (4698) (M. lysodeikticus) & - & $\mathrm{Ml}$ & ATCC \\
\hline
\end{tabular}


TABLE 1-Continued

\begin{tabular}{|c|c|c|c|}
\hline Organism $^{a, b}$ & $\begin{array}{l}\text { Kovacs oxi- } \\
\text { dase reac- } \\
\text { tion }\end{array}$ & $\begin{array}{l}\text { Fig. } 1 \text { abbre- } \\
\text { viations }\end{array}$ & Source \\
\hline Norcardia asteroides (3308) & - & $\mathrm{Na}$ & ATCC \\
\hline Proteus morganii & - & $\mathrm{Pm}$ & U Houston \\
\hline Proteus vulgaris & - & $\mathrm{Pv}$ & U Houston \\
\hline Pseudomonas maltophilia (13637) & - & Psm & ATCC \\
\hline Staphylococcus aureus (6538) & - & Sau & UTHMS \\
\hline Staphylococcus aureus & - & Sau & U Houston \\
\hline Streptomyces griseus (10137) & - & $\mathrm{Sg}$ & ATCC \\
\hline $\begin{array}{l}\text { Vibrio cholerae biotype proteus }(7708)(V . \\
\text { metschnikovii) }\end{array}$ & - & VM & ATCC \\
\hline \multicolumn{4}{|l|}{ Group IV } \\
\hline Bacillus pumilus 70 & - & $\mathrm{Bp}$ & UTHGSBS \\
\hline Bacillus subtilis (B. vulgatus) & - & $\mathrm{Bv}$ & UTHGSBS \\
\hline Gaffkya tetragena (10875) & - & $\mathrm{Gt}$ & UTHMS \\
\hline Gaffkya tetragena & - & Gt & U Houston \\
\hline Klebsiella pneumoniae (13883) & - & $\mathrm{Kp}$ & UTHMS \\
\hline Lactobacillus casei & - & Lc & UT Galveston \\
\hline Pediococcus cerevisiae (8081) & - & Pc & UT Galveston \\
\hline Salmonella typhimurium (6444) & - & St & UTHMS \\
\hline Serratia marcescens & - & $\mathrm{Sm}$ & U Houston \\
\hline Staphylococcus aureus (S. albus) & - & $\mathrm{S}$ & U Houston \\
\hline Streptococcus faecalis (8043) & - & Sf & UT Galveston \\
\hline Streptococcus faecalis (9790) & - & $\mathrm{Sf}$ & UT Galveston \\
\hline Streptococcus pneumoniae (6303) & - & Spn & ATCC \\
\hline Streptococcus pyogenes (10389) & - & Spy & UTHMS \\
\hline Vitreoscilla stercoraria (15218) & - & $\mathrm{Vs}$ & NTSU \\
\hline Xanthomonas phaseoli (9563) & - & $\mathrm{Xp}$ & ATCC \\
\hline
\end{tabular}

a Numbers in parentheses indicate American Type Culture Collection (ATCC) numbers, all other numbers (or letters) represent strain designations.

${ }^{b}$ Names in parentheses indicate the nomenclature used in the 7th edition of Bergey's Manual of Determinative Bacteriology, 1957.

c Abbreviations: M C Wisconsin, Medical College of Wisconsin; U Maryland, University of Maryland; UT Austin, University of Texas at Austin; UTHMS, University of Texas at Houston Medical School; NTSU, North Texas State University; UTHGSBS, University of Texas at Houston Graduate School of Biomedical Sciences; U Sussex, University of Sussex; Houston HD, Houston Health Department; UT Galveston, University of Texas Medical Branch at Galveston; ATCC, American Type Culture Collection.

chemical autoxidation. reaction had occurred that would have interfered with the bacterial terminal oxidase assay (7). All activities for the ascorbateTMPD oxidase assay are reported using the conventional $Q_{\mathrm{O}_{2}}$ value which was defined above.

\section{RESULTS}

Figure 1 shows a composite analysis of the data obtained from our survey study. The absolute $\mathrm{Q}_{0_{2}}$ TMPD oxidation value, corrected for the endogenous respiration by subtraction, is plotted as a function of the TMPD/endogenous ratio. The abbreviations used in Fig. 1 (representing the generic names of the bacteria) are identified in Table 1, which lists alphabetically, for each group, the genus and species name of bacteria, the ATCC number or other strain designation, the Kovacs oxidase reaction, and the source(s) from which the microorganism(s) was obtained. In this figure the ordinate expresses on a logarithmic scale the corrected $\mathbf{Q}_{\mathrm{O}_{2}}$ value for TMPD oxidation, which was obtained by subtracting the endogenous respiration value (TMPD - endogenous); the endogenous value was defined as the respiratory $\mathrm{Q}_{\mathrm{O}_{2}}$ value obtained in the absence of ascorbate-TMPD. The abscissa expresses the ratio of the uncorrected TMPD $\mathrm{Q}_{\mathrm{O}_{2}}$ value relative to the endogenous respiration value also plotted on a logarithmic scale. $\mathrm{A} \mathrm{Q}_{\mathrm{O}_{2}}$ (TMPD/endogenous) ratio of 100 means that the TMPD oxidation value is 100 times greater than the endogenous, whereas a $\mathrm{Q}_{\mathrm{O}_{2}}$ (TMPD/endogenous) ratio of 1 indicates that TMPD oxidation and endogenous values are the same; i.e., there is essentially no TMPD oxidation. This type of double logarithmic plot enabled the bacteria to be grouped according to their capability to oxidize TMPD; the highest oxidation values represent those farthest away from the origin, i.e., those found in group I. The least active are those listed in group IV. The data shown in Fig. 1 correlate perfectly with 
the Kovacs oxidase reaction (see Table 1); groups I and II contain all Kovacs oxidasepositive bacteria whereas in groups III and IV one finds all the oxidase-negative organisms. In fact the TMPD oxidase assay was so sensitive that it allowed for a further separation of Kovacs oxidase-positive bacteria. Those in group I had very high TMPD oxidase $\mathrm{Q}_{\mathrm{O}_{2}}$ values, whereas those organisms in group II had, on a relative basis, only moderately active TMPD oxidase activity. A separation of Kovacs oxidase-positive bacteria from the -negative bacteria represents that line which surrounds the organisms listed in group III, namely, the bacteria which have a low (but still measurable) TMPD oxidase $\mathbf{Q}_{\mathrm{O}_{2}}$ value. The organisms in group IV were essentially devoid of TMPD oxidase activity.

The Kovacs oxidase-positive bacteria listed in group I had high corrected TMPD $\mathrm{Q}_{\mathrm{O}_{2}}$ values which ranged from 393 to 2,164 as well as high TMPD/endogenous ratios ranging from 23 to 197. In this group one finds the Achromobacter, Azotobacter, Neisseria, Pseudomonas, and Spirillum species. Azotomonas insolita had the highest $Q_{r_{2}}$ value of any of the bacteria surveyed; it possessed a corrected TMPD $Q_{\mathrm{O}_{2}}$ oxidation value of 2,164 and a TMPD/endogenous ratio of 197. The oxidase-positive bacteria listed in group II exhibited intermediate but still relatively high TMPD oxidation rates, the $Q_{0_{2}}$ values ranging from 27 to 280 and TMPD/endogenous ratios ranging from 5 to 46 . Organisms in this group included members of Aeromonas, Flavobacterium, Micrococcus, and Vibrio species. Micrococcus luteus is also in this group and is considered to be oxidase variable (1). It is this group of organisms which is most closely associated with those found in group III, which include all Kovacs oxidase-negative bacteria. The organisms in group III had low but still measurable TMPD oxidase activities which ranged from 3 to 33 and also low TMPD/endogenous ratios ranging from 1 to 5 . This group includes many organisms of the family Enterobacteriaceae as well as Acinetobacter, Bacillus, and Mycobacterium species. Six Escherichia coli strains (10 isolates), when analyzed for TMPD oxidase activity, fell within the range of activity defined for group III. It is of interest to note the relative scatter of points obtained for these various $E$. coli strains; all appear to be well confined within this group. One point of particular interest would be the extent TMPD oxidation might occur with the "oxidase positive" $E$. coli mutant $\mathrm{HfrH} 1060$, which has already been somewhat partially characterized in the literature (18).
The organisms listed in group IV could not oxidize TMPD to any meaningful degree; the bacteria in this group had corrected TMPD oxidase rates ranging from 0 to 3 as well as very low TMPD/endogenous ratios which ranged from 1 to 2 . The genera of organisms falling in group IV include Gaffkya, Lactobacillus, Pediococcus, and Streptococcus as well as some species of the family Enterobacteriaceae. The inability of these organisms to carry out TMPD oxidation can be attributed either to: (i) the lack of intracellular $c$-type cytochromes, or the absence of a functional terminal oxidase, i.e., cytochromes $o, a_{1}, a_{2}$, or $a+a_{3}$ (in organisms possessing solely the functional flavoprotein-type electron transport systems) (6); or (ii) the fermentative-type organisms which completely lack cytochrome components, as in the case of the lactic acid bacteria (4).

Another artificial electron donor, 2,6-dichloroindophenol (DCIP), could readily replace TMPD in measuring the terminal oxidase activity using bacterial whole cells. For Azotobacter vinelandii, the rate of DCIP oxidation $\left(\mathrm{Q}_{\mathrm{O}_{2}}\right.$ value) was approximately one-half that obtained with TMPD when comparisons were made at the same concentration levels. The kinetics of DCIP oxidation by $A$. vinelandii whole cells, relative to that of TMPD oxidation, has been described in detail elsewhere (8).

\section{DISCUSSION}

From this survey study, it is possible to make certain generalizations concerning TMPD oxidation by bacterial whole cells. This oxidation has long been known to measure terminal oxidase function as does the cytochrome $c$ oxidase reaction $(7-10,12)$. As we have shown, standardized resting-cell suspensions, prepared from cells grown under "standard" conditions and harvested at the late log phase, can oxidize TMPD. This reaction can then be measured by manometry, and the data obtained can be compared with the, hitherto qualitative Kovacs oxidase test. The reproducibility of the $Q_{t_{2}}$ value obtained for the TMPD oxidation by different strains of Branhamella (Neisseria) catarrhalis, $V$. parahaemolyticus, and $E$. coli strongly suggests that the estimation of the TMPD oxidase $\mathbf{Q}_{\mathrm{O}_{2}}$ value will have taxonomic value, particularly if the cellular oxidation rates can be compared at the identical phases of the bacterial growth cycle under nutritionally defined conditions.

This study also has allowed for the resolution of that point which separates the Kovacs oxidase-positive from oxidase-negative bacteria. 


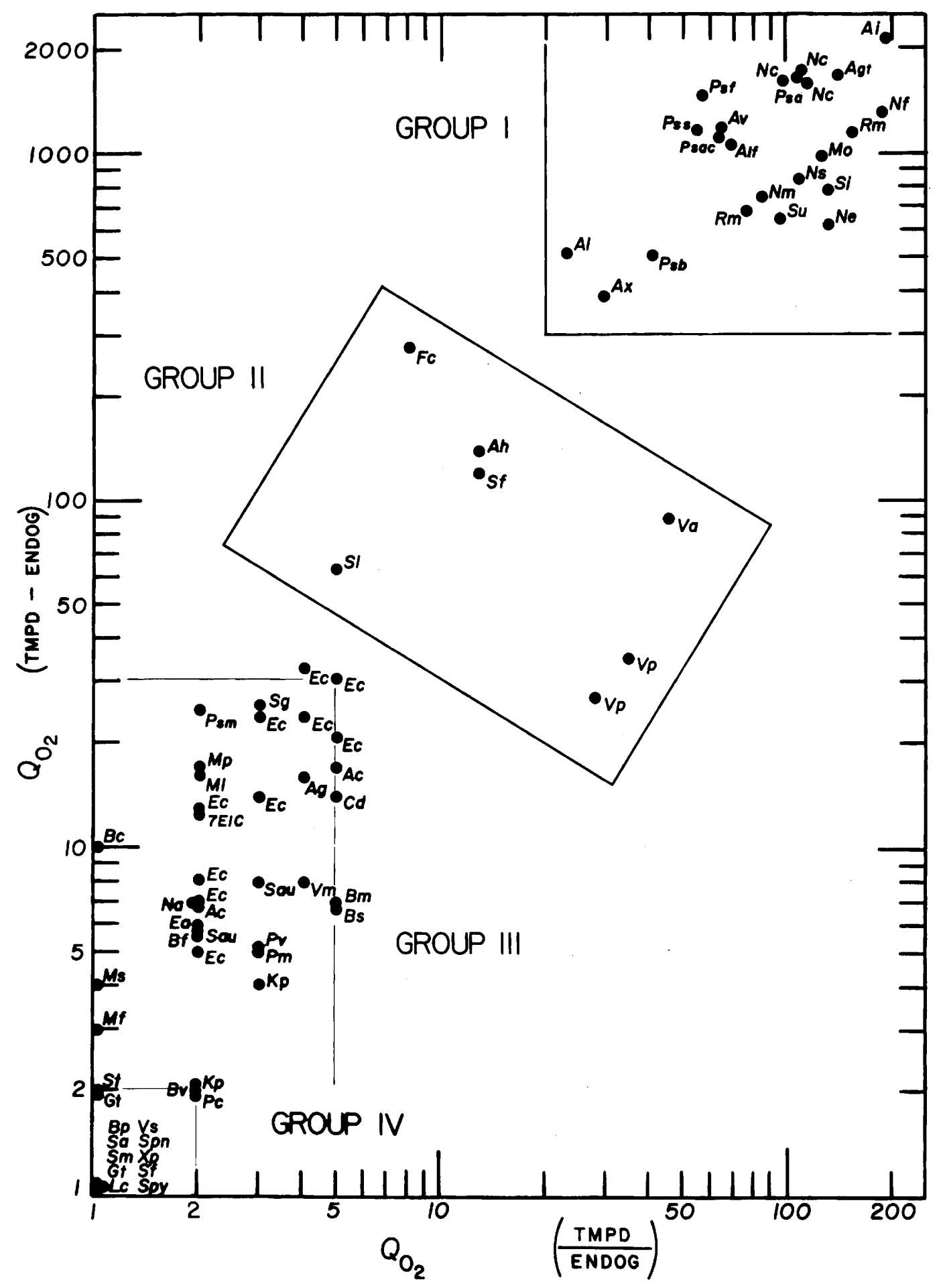


This represents a $Q_{\mathrm{O}_{2}}$ value for TMPD oxidation of 33 (after correction for the endogenous) and a TMPD/endogenous ratio equal to 5 . The $\mathrm{Q}_{\mathrm{O}_{2}}$ values for endogenous respiration are very important for group classification as exemplified by the data obtained for the intensely Kovacs oxidase-positive $V$. parahaemolyticus and the oxidase-negative $E$. coli. Both organisms show absolute TMPD oxidation $\mathrm{Q}_{\mathrm{O}_{2}}$ values of approximately 30; however, $E$. coli shows a TMPD/ endogenous ratio of approximately 5 , whereas $V$. parahaemolyticus has a ratio of about 30 . This difference is reflected solely in the endogenous $\mathrm{Q}_{\mathrm{O}_{2}}$ respiration value; this value was high for $E$. coli, but not measurable for most of the Vibrio species analyzed in our study. Therefore, the estimation of the endogenous would undoubtedly play a major role in the group classification, particularly with oxidase-positive organisms that have relatively low TMPD $\mathrm{Q}_{\mathrm{O}_{2}}$ oxidase rates.

As mentioned previously, the inability of group IV bacteria to oxidize TMPD can be attributed to the absence of a $c$-type cytochrome and/or to the lack of a functional terminal oxidase, i.e., cytochrome $o, a+a_{3}$, etc., or to both. Many of the bacteria listed in group IV have previously been shown to lack cytochrome components (4); others only possess the flavoprotein-type electron transport systems that are completely devoid of cytochrome components (6). The importance of a $c$-type cytochrome being present for measuring terminal TMPD oxidase activity is demonstrated by Pseudomonas maltophilia, which of all the pseudomonads studied has been shown to lack cytochrome $c$ (19). This organism and Vibrio cholerae biotype proteus were intentionally included in our survey study because both were therefore exceptions to the other species analyzed within these genera (20). It has never been established why $V$. cholerae biotype pro- teus is oxidase negative, unlike almost all other Vibrio species.

Another point of interest concerns the Kovacs oxidase-negative organisms listed in group III. Although many organisms in this group have some capability to oxidize TMPD, as does $E$. coli, they are still considered oxidase negative. Of interest, however, are organisms of the genera Mycobacterium, Nocardia, and Streptomyces and of some Bacillus species which are "obligately aerobic" yet lack significant TMPD oxidation capability and are in essence Kovacs oxidase negative. This would imply that, in such oxidase-negative obligate aerobes, there must be a type of terminal oxidase that allows for some residual TMPD oxidation or that perhaps a permeability problem exists which prevents TMPD from entering the cell and thus does not allow this electron donor to be oxidized at the high rates observed for most oxidasepositive organisms. This residual TMPD oxidation rate must be of some importance as it appears to be of a magnitude that allows these organisms to be differentiated from those found in group IV, which completely lack TMPDoxidizing capability. Such aerobic organisms therefore have terminal oxidases capable of reacting with molecular oxygen, yet the apparent oxidative turnover rate cannot be measured maximally by assaying for TMPD oxidation. A terminal oxidase from $M y c o b a c t e r i u m ~ p h l e i$ has already been isolated which consists of a complex containing cytochrome $a+a_{3}$ and cytochrome $o(16,17)$. The published reports indicated that these cytochrome components are reducible by TMPD but that the purified mycobacterial terminal oxidase apparently does not oxidize TMPD catalytically. In contrast to the studies on $M$. phlei, in A. vinelandii, an organism which falls into group I, it has been possible to isolate and purify a terminal cytochrome oxidase using the ascorbate-TMPD oxidation

FIG. 1. Double logarithmic plot showing the grouping analysis of bacterial terminal oxidase activity for whole cells of a large number of heterotrophically grown bacteria. A turbidimetrically standardized restingcell suspension was prepared for each organism tested, all cells (with the noted exception of those of Vitreoscilla stercoraria) (i) being grown at $30 \mathrm{C}$, on nutrient broth containing both $1 \%$ sucrose and $0.5 \%$ yeast extract, and (ii) harvested at the late logarithmic growth phase. Each point represents the $Q_{\mathrm{O}_{2}}$ value (microliters of $\mathrm{O}_{2}$ consumed per hour per milligram [dry weight] at $30 \mathrm{C}$ ) for TMPD oxidation for each of the microorganisms used in this study; the abbreviations and sources are identified in Table 1 . The ordinate shows the corrected absolute TMPD $Q_{\mathrm{O}_{2}}$ value (TMPD - endogenous), which is plotted as a function of the TMPD/ endogenous ratio shown by the abscissa. The bacterial species falling within groups I and II are all Kovacs oxidase positive, whereas those species within groups III and IV are oxidase negative. The line which surrounds the oxidase-negative organisms in group III represents the points which separate the oxidase-positive from the oxidase-negative bacteria. Oxidase-positive whole cells exhibited a minimal TMPD oxidase $Q_{\mathrm{O}_{2}}$ value of 33 (after subtracting for the endogenous respiration), and the TMPD oxidase rate also had to be at least five times greater than the endogenous $Q_{\mathrm{O}_{2}}$ value. Endogenous respiration was measured under the identical physiological conditions used to determine TMPD oxidation; however, no ascorbate nor TMPD was present in the assay flask. 
assay as described herein; the purified Azotobacter terminal oxidase consisted of a cytochrome $c_{4}+c_{5}$ : cytochrome $o$ complex (T. Mueller and P. Jurtshuk, Abstr. Annu. Meet. Am. Soc. Microbiol. 1973, p. 136, p. 193).

Lastly, two organisms falling into group IV also show some interesting metabolic features that pertain in general to their oxidative metabolism. Organisms of this group would have corrected TMPD $\mathrm{Q}_{\mathrm{O}_{2}}$ values that would be barely measurable. Xanthomonas phaseoli, an oxidase-negative bacterium, although possessing an oxidative respiratory metabolism (2), cannot oxidize TMPD. This suggests that this organism possesses a terminal oxidase that cannot react with TMPD to any measurable extent. The filamentous trichome-forming Vitreoscilla stercoraria (which lacks flagella but possesses gliding motility) is also found in group IV. This latter organism appears to lack both $a$ - and $c$-type cytochromes $(5,15,22)$ but contains cytochrome $o$, which has recently been purified $(15,22)$. Vitreoscilla lacks TMPD oxidative capability, and even its electron transport particle cannot oxidize TMPD (5), and this inability to oxidize TMPD might be due to the absence of the $c$-type cytochrome as was the case for $P$. maltophilia.

All indications to date suggest that high (group I) or moderately high (group II) TMPD oxidase activity will be found in those bacteria which possess an integrated terminal or cytochrome oxidase enzyme complex consisting of both a $c$-type cytochrome and a terminal oxidase component such as cytochrome $o$ and/or $a$ $+a_{3}$, possibly in combination with cytochrome $a_{1}$ or $a_{2}$. This latter point has been thoroughly discussed in a recent review article (12).

\section{ACKNOWLEDGMENTS}

We wish to thank the following investigators and their affiliate institutions for providing the bacterial cultures that were used in our survey study: B. Wesley Catlin, the Medical College of Wisconsin; Rita Colwell, University of Maryland; the late J. W. Foster, University of Texas at Austin; Millicent E. Goldschmidt, University of Texas at Houston Medical School; S. Kester, North Texas State University; T. S. Matney for the Escherichia coli strains and Manley Mandel for all of the other cultures that were obtained from the University of Texas at Houston Graduate School of Biomedical Sciences; J. R. Postgate, University of Sussex; Reuben Wende, Houston Health Department; Robert C. Wood, University of Texas Medical Branch at Galveston; as well as the American Type Culture Collection, Rockville, Md. (ATCC). The authors also acknowledge the valuable technical assistance of Olga Marcucci during the early phases of this survey study. This investigation was supported by Public Health Service grant GM 17607-04 from the National Institute of General Medical Sciences and Biomedical Sciences Support grant 5 SO5 RR07147-03.

\section{REPRINT REQUESTS}

Address reprint requests to: Dr. Peter Jurtshuk, Department of Biology, University of Houston, Houston, Tex. 77004 .

\section{LITERATURE CITED}

1. Boswell, P. A., G. F. Batstone, and R. G. Mitchell. 1972. The oxidase reaction in the classification of the Micrococcaceae. J. Med. Microbiol. 5:267-269.

2. Buchanan, R. E., and N. E. Gibbons (ed.). 1974. Bergey's manual of determinative bacteriology, 8 th ed. Williams and Wilkins Co., Baltimore.

3. Conover, T. E. 1970. On the occurrence of respiratory components in calf thymus nuclei. II. Cytochrome oxidase activity. Arch. Biochem. Biophys. 136:551562.

4. Deibel, R. H., and J. B. Evans. 1960. Modified benzidine test for the detection of cytochrome-containing respiratory systems in micro-organisms. J. Bacteriol. 79:356-360.

5. Dietrich, W. E., Jr., and J. Biggins. 1971. Respiratory mechanisms in the Flexibacteriaceae: terminal oxidase systems of Saprospira grandis and Vitreoscilla species. J. Bacteriol. 105:1083-1089.

6. Dolin, M. I. 1961. Cytochrome-independent electron transport enzymes in bacteria, p. 425-460. In I. C. Gunsalus and R. Y. Stanier (ed.), The bacteria, vol. 2. Academic Press Inc., New York.

7. Jurtshuk, P., P. R. Aston, and L. Old. 1967. Enzymatic oxidation of tetramethyl- $p$-phenylenediamine and $p$ phenylenediamine by the electron transport particulate fraction of Azotobacter vinelandii. J. Bacteriol. 93:1069-1078.

8. Jurtshuk, P., O. M. Marcucci, and D. N. MeQuitty. 1975. Tetramethyl-p-phenylenediamine oxidase reaction in Azotobacter vinelandii. Appl. Microbiol. 30: 951-958.

9. Jurtshuk, P., A. D. May, L. M. Pope, and P. R. Aston. 1969. Comparative studies on succinate and terminal oxidase activity in microbial and mammalian electron transport systems. Can. J. Microbiol. 15:797807.

10. Jurtshuk, P., and T. W. Milligan. 1974. Quantitation of the tetramethyl-p-phenylenediamine oxidase reaction in Neisseria species. Appl. Microbiol. 28:10791081.

11. Jurtshuk, P., and T. W. Milligan. 1974. Preliminary characterization studies on the Neisseria catarrhalis electron transport chain. J. Bacteriol. 120:552-555.

12. Jurtshuk, P., T. J. Mueller, and W. C. Acord. 1975. Bacterial terminal oxidases. CRC Crit. Rev. Microbiol. 3:399-468.

13. Jurtshuk, P., and L. Old. 1967. Cytochrome $c$ oxidation by the electron transport fraction of Azotobacter vinelandii J. Bacteriol. 95:1790-1797.

14. Kovacs, N. 1956. Identification of Pseudomonas pyocyanea by the oxidase reaction. Nature (London) 178:703.

15. Liu, C. Y., and D. A. Webster. 1974. Spectral characteristics and interconversions of the reduced, oxidized and oxygenated forms of purified cytochrome o. J. Biol. Chem. 249:4261-4266.

16. Revsin, B., E. D. Marquez, and A. F. Brodie. 1970 . Cytochromes from Mycobacterium phlei. I. Isolation and spectral properties of a mixture of cytochromes $\left(a \times a_{3}\right)$ (o). Arch. Biochem. Biophys. 139:114-120.

17. Revsin, B., E. D. Marquez, and A. F. Brodie. 1970 Cytochromes from Mycobacterium phlei. II. Ascorbate reduction of an isolated cytochrome $\left(a+a_{3}\right)(0)$ complex. Arch. Biochem. Biophys. 136:563-573. 
18. Shipp, W. S. 1972. Cytochromes of Escherichia coli. Arch. Biochem. Biophys. 150:459-472.

19. Stanier, R. Y., N. J. Palleroni, and M. Doudoroff. 1966.

The aerobic pseudomonads: a taxonomic study. J. Gen. Microbiol. 43:159-271.

20. Steel, K. J. 196i. The oxidase reaction as a taxonomic tool. J. Gen. Microbiol. 25:297-306.

21. Steel, K. J. 1962. The oxidase activity of staphylococci. J. Appl. Bacteriol. 25:445-447.

22. Webster, D. A., and C. Y. Liu. 1974. Reduced nicotinamide adenine dinucleotide-cytochrome o purified from Vitreoscilla. J. Biol. Chem. 249:4257-4260. 